\title{
Dysfunction of cross-frequency phase-phase coupling in primary dysmenorrhea: a resting magnetoencephalographic study
}

Pin-Shiuan Lee ${ }^{1 *}$, Yong-Sheng Chen ${ }^{2}$, Jen-Chuen Hsieh ${ }^{3,4}$, Li-Fen Chen ${ }^{3,4}$

From Twenty First Annual Computational Neuroscience Meeting: CNS*2012

Decatur, GA, USA. 21-26 July 2012

Cross-frequency synchronization between neuronal ensembles has been studied recently, which is related to coupling between neuronal oscillations of different frequency contents [1]. This study aimed at the investigation of how cross-frequency phase-phase coupling of local network during rest is modulated by pain experience. Ten primary dysmenorrhea (PDM) females suffering lower abdominal pain during menstrual phase and ten age-matched healthy females were enrolled. Three-minute eye-open resting magnetoencephalographic (MEG) signals of each individual during menstrual phase were recorded using a 306-channel MEG system. For

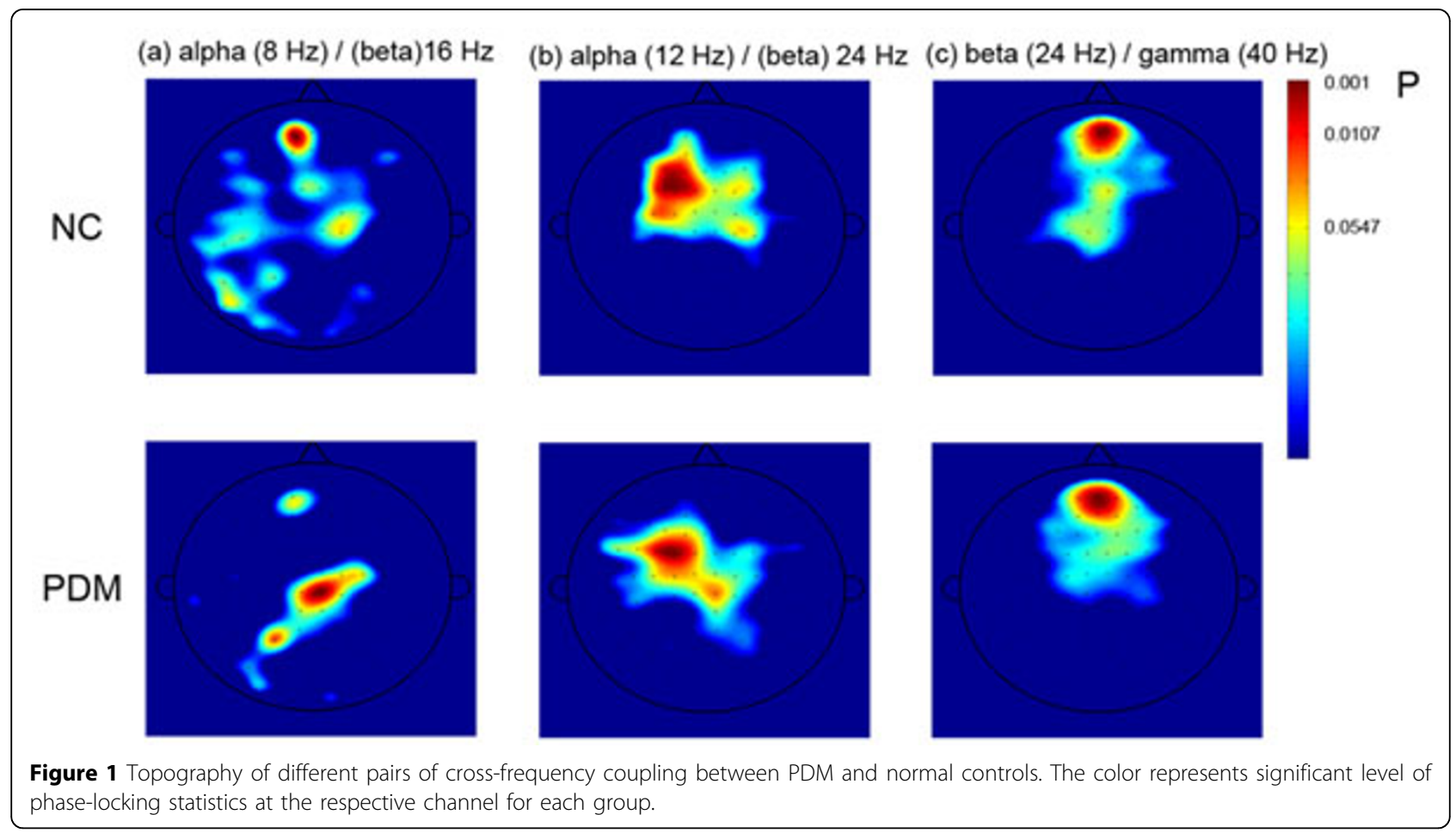

\footnotetext{
* Correspondence: pshiuan@gmail.com

${ }^{1}$ Institute of Biomedical Informatics, National Yang-Ming University, Taipei

112, Taiwan

Full list of author information is available at the end of the article
}

(c) 2012 Lee et al; licensee BioMed Central Ltd. This is an Open Access article distributed under the terms of the Creative Commons 
each channel, synchronization value of cross-frequency coupling was estimated by calculating phase-locking statistics of phase differences between two frequency bands, including 2, 4, 8, 12, 16, 24, 32, and $40 \mathrm{~Hz}$, respectively. The results of one-sample binomial test showed that in low alpha/beta $(8 / 16 \mathrm{~Hz})$ oscillations, the PDM group displayed coupling in the medial parietal area whereas no coupling in the control group (Figure 1(a)). On the other hand, coupling at the prefrontal area found in the NC group was not found in the PDM group. These two regions have been reported as part of resting state networks [2]. No difference of coupling between the PDM and control groups was found in other combinations of frequency pairs, for instance, high alpha/beta (Figure 1 (b)) and beta/gamma (Figure 1(c)).

\section{Conclusion}

Our findings implicate that pain experience may modulate phase-phase coupling of alpha/beta oscillation, which might disrupt integration between nearby neural population in the human neocortex at rest.

\section{Acknowledgements}

This study was supported in part by the National Science Council (NSC 1002629-B-010-001 and 100-2628-E-009-006) and Yen Tjing Ling Medical

Foundation (Cl-100-5).

\section{Author details}

${ }^{1}$ Institute of Biomedical Informatics, National Yang-Ming University, Taipei 112, Taiwan. ${ }^{2}$ Department of Computer Science, National Chiao Tung University, Hsinchu 300, Taiwan. ${ }^{3}$ Institute of Brain Science, National YangMing University, Taipei 112, Taiwan. ${ }^{4}$ Integrated Brain Research Laboratory, Department of Medical Research and Education, Taipei Veterans General Hospital, Taipei 112, Taiwan.

Published: 16 July 2012

\section{References}

1. Nikulin V, Brismar T: Phase synchronization between alpha and beta oscillations in the human electroencephalogram. Neuroscience 2006 137(2):647-657.

2. Van Den Heuvel M, Mandl R, Pol HH: Normalized cut group clustering of resting-state FMRI data. PLoS One 2008, 3(4):e2001.

doi:10.1186/1471-2202-13-S1-P168

Cite this article as: Lee et al:: Dysfunction of cross-frequency phasephase coupling in primary dysmenorrhea: a resting

magnetoencephalographic study. BMC Neuroscience 2012 13(Suppl 1) P168.

\section{Submit your next manuscript to BioMed Central} and take full advantage of:

- Convenient online submission

- Thorough peer review

- No space constraints or color figure charges

- Immediate publication on acceptance

- Inclusion in PubMed, CAS, Scopus and Google Scholar

- Research which is freely available for redistribution

Submit your manuscript at www.biomedcentral.com/submit
C Biomed Central 